\title{
Quantification of neurodegeneration by measurement of brain-specific proteins
}

\author{
A. Petzold * D. Baker G. Pryce G. Keir E.J. Thompson \\ G. Giovannoni \\ UCL Institute of Neurology, Department of Neuroinflammation, University College \\ London, Queen Square, London WC1N 3BG, United Kingdom
}




\section{Abstract}

Quantification of neurodegeneration in animal models is typically assessed by timeconsuming and observer-dependent immunocytochemistry. This study aimed to investigate if newly developed ELISA techniques could provide an observer-independent, cost-effective and time saving tool for this purpose.

Neurofilament-heavy chain $\left(\mathrm{NfH}^{\text {SMI35 }}\right)$, astrocytic glial fibrillary acidic protein (GFAP), S100B and ferritin, markers of axonal loss, gliosis, astrocyte activation and microglial activation respectively, were quantified in the spinal cord homogenates of mice with chronic relapsing experimental allergic encephalomyelitis (CREAE, $\mathrm{n}=8$ ) and controls $(n=7)$. Levels of GFAP were found to be 3-fold elevated in CREAE (13 $\mathrm{ng} / \mathrm{mg}$ protein) when compared to control animals $(4.5 \mathrm{ng} / \mathrm{mg}$ protein, $\mathrm{p}<0.001)$. The inverse was observed for $\mathrm{NfH}^{\text {SMI35 }}(21 \mathrm{ng} / \mathrm{mg}$ protein vs. $63 \mathrm{ng} / \mathrm{mg}$ protein, p<0.001), ferritin (542 ng/mg protein vs. $858 \mathrm{ng} / \mathrm{mg}$ protein, $\mathrm{p}<0.001)$ and $\mathrm{S} 100 \mathrm{~B}$ (786 ng/mg protein vs $2080 \mathrm{ng} / \mathrm{mg}$ protein, N.S.). These findings were confirmed by immunocytochemistry, which demonstrated intense staining for GFAP and decreased staining for $\mathrm{NfH}^{\text {SMI35 }}$ in CREAE compared to control animals.

These findings indicate that axonal loss and gliosis can be estimated biochemically using the newly-developed ELISA assays for $\mathrm{NfH}^{\text {SMI35 }}$ and GFAP. These assays may facilitate the quantification of pathological features involved in neurodegeneration.

Key words: Surrogate marker, EAE, S100B, GFAP, NfH ${ }^{S M I 35}$, Ferritin, ELISA, brain-specific proteins

\footnotetext{
* Department of Neuroinflammation, Institute of Neurology, Queen Square, London WC1N 3BG, United Kingdom. Tel.: +44 2078373611 ext. 4204, Fax +44 207837 8553, Email: a.petzold@ion.ucl.ac.uk
} 
Failure to halt the progression of multiple sclerosis (MS) with immunomodulatory agents and recent pathological insights has shown neurodegeneration to be an important pathogenic component of MS [1-3] and provides impetus for designing and assessing treatment paradigms in animal models. Axonal loss correlates with permanent neurological disability in chronic relapsing experimental allergic encephalomyelitis (CREAE) [1] and is typically assessed using time-consuming and observer-dependent immunocytochemistry $[1,2]$. Therefore simple quantitative surrogates for neurodegeneration would be useful.

In immunocytochemistry, GFAP has been used as a marker for astrogliosis and S100B for activation of astrocytes, ferritin as a marker for microglial activation and neurofilaments (Nf) as a marker for axonal damage [3-6]. This study examines the potential of ELISA-based methods to assess neurodegeneration in CREAE.

\section{Methods}

Adult Biozzi ABH mice (6-8 weeks old) were housed in a light- and temperature -controlled room and matched for age and sex in the experiment $(50 \%$ female in the CREAE and $43 \%$ female in the control group). CREAE was induced as described previously [7]. In brief: Animals were injected s.c. in 2 sites of the flank with a total of $0.3 \mathrm{ml}$ of Freund's adjuvant:PBS (1:1) containing 1mg of syngeneic mouse spinal cord homogenate emulsified in Freund's incomplete adjuvant supplemented with 60g mycobacteria (Mycobacterium tuberculosis H37Ra and M.butyricum (8:1)on day 0 and again on day 7. Animals were scored clinically on a scale ranging from 0 to 6 , where 0 indicated a normal animal, 1 a limp tail, 2 loss of the inverted righting reflex, 3 par- 
tial hind limb paralysis, 4 complete hindlimb paralysis, 5 moribund and 6 death [7]. After 60-80 days post-inoculation, the chronic phase of the disease had been reached [8] and the animals were killed by $\mathrm{CO}_{2}$ intoxication. Immediately after death the spinal column was cut in the cervical and lumbar regions. A needle was inserted into the lumbar vertebral column and the spinal cord ejected into an Eppendorf tube by a pressurised injection of saline. The spinal cord which is the primary site of pathology in this model, [7] was snapfrozen and stored at $-70^{\circ} \mathrm{C}$ until further analysis. Frozen tissue was used for immunocytochemistry as described using polyclonal rabbit anti-cow GFAP IgG (DAKO, Denmark) or polyclonal rabbit anti-bovine NfH IgG (Sigma, UK) and FITC labelled swine anti-rabbit IgG (Dako) [7,8]. Photographs of the fluorescien images were digitally transformed into black-and--white slides for better visualisation.

For protein analysis the spinal cord was suspended in sample buffer 1:5 v/w containing a protease inhibitor cocktail (Sigma, No P 8340). Samples were homogenised on ice by sonication and triturated 3 times through 19 and 21 gauge needles. Lipids were extracted by adding di-iso-propyl ether (1: 5,000) prior to centrifugation at $20,000 \mathrm{~g}$. The supernatant was stored at $-70^{\circ} \mathrm{C}$.

S100B, GFAP and ferritin were measured as described $[9,10,6]$. Total protein was measured using the standard Lowry method. The neurofilament heavy chain $\left(\mathrm{NfH}^{\text {SMI35 }}\right)$ was measured by ELISA: 96-well microtitre plates were coated with $0.05 \mathrm{M}$ carbonate buffer containing monoclonal anti $\mathrm{NfH}^{\text {SMI35 }}$ (Sternberg Monoclonals Incorporate, 10 Burwood Court, Lutherville, MD 21093, SMI35) diluted 1:5000. The plates were washed with $0.67 \mathrm{M}$ barbitone buffer containing $5 \mathrm{mM}$ EDTA, 0.1\% BSA and 0.05\% Tween. The plates were blocked with $1 \%$ BSA and washed. Spinal cord homogenate was diluted 
in $0.67 \mathrm{M}$ barbitone buffer containing $5 \mathrm{mM}$ EDTA. After incubation and wash a rabbit polyclonal anti-NfH ${ }^{S M I 35}$ (Sigma) was diluted (1:1000) in the sample buffer. After incubation and wash HRP-conjugated polyclonal swine anti-rabbit IgG (DAKO, Denmark) was used as detecting antibody (1:1000). The OPD (Sigma) colour reaction was stopped with $1 \mathrm{M}$ hydrochloric acid and the absorbances were read at 492 and $405 \mathrm{~nm}$. All samples were processed in duplicate. The antigen concentration was calculated from an internal standard curve ranging from $0 \mathrm{ng} / \mathrm{mL}$ to $500 \mathrm{ng} / \mathrm{mL}$ (HPLC purified bovine $\mathrm{NfH}^{\text {SMI35 }}$, Affiniti Research Products, Exeter, UK) with an inter-assay covariation of less then $15 \%$. For clarity $\mathrm{NfH}^{S M I 35}$ is referred to as $\mathrm{NfH}$ if measured by this ELISA, based on the SMI35 capture monoclonal antibody.

All statistical analyses and graphs were performed using SAS software (V8.2 SAS Institute, Inc., Cary, North Carolina, USA). Individual values, the median, interquartile range (25-75\% box) and 0-100\% range (whiskers) were shown in the figures because of the non-normal distribution. Statistical comparison was performed using Fisher's exact test $(\alpha=0.05)$. The cut-off for categorical data analysis was set to $0 \%$ or $100 \%$ cumulative frequency of the control group as appropriate. $\mathrm{P}-$ values of $<0.05$ were considered significant.

\section{Results}

A 3-fold increase of median GFAP levels (13 ng/mg protein) in chronic EAE animals was observed if compared to control animals $(4.5 \mathrm{ng} / \mathrm{mg}$ protein, Fig. $1 \mathrm{~A})$. In addition a more intense immunocytochemical staining was observed in CREAE mice. The white matter of CREAE animals showed intense staining for GFAP and widespread astrogliosis. Astrocytes of the CREAE grey matter 
were of larger configuration with a greater number of extending processes (Figure $2 \mathrm{~A}$ ).

Levels of $\mathrm{NfH}^{\text {SMI35 }}$ were approximately 3-fold lower in CREAE (21 ng/mg protein) than in control mice (63 ng/mg protein, Fig. $1 \mathrm{~B}$ ). The staining for $\mathrm{NfH}$ was more intense in the white matter of control animals (Figure $2 \mathrm{~B}$ ). It is of note that the continuity of axonal projections could be followed. In CREAE animals NfH staining was less intense, axonal continuity almost disappeared and many axonal end-bulbs were observed (Figure 2 B).

Ferritin was less then 2-fold lower in CREAE (547 ng/mg protein) compared to CTRL mice (858 ng/mg protein, Fig. $1 \mathrm{C}$ ), median S100B levels were about 2.6-fold lower in CREAE (786 ng/mg protein) than in CTRL mice (2080 ng/mg protein, Fig. 1 D).

Seven out of 8 (88\%) CREAE animals had GFAP levels above the cut-off and by definition none $(0 \%)$ of the control animals had GFAP levels above the cut-off $(\mathrm{p}<0.001)$. For $\mathrm{NfH}^{S M I 35} 0 / 8(0 \%)$ of the CREAE and $7 / 7(100 \%)$ of the control animals had levels above the cut-off $(p<0.001)$. For ferritin $1 / 7$ (13\%) of the CREAE and $7 / 7(100 \%)$ of the control mice had levels above cutoff (p<0.001). For S100B 3/8 (38\%) of the CREAE and 0/7 (100\%) of the control mice had levels above the cut-off, but this did not reach statistical significance. For the small number of animals investigated we found no statistically significant difference in proportions of animals with moderately (score $\leq 4)$ vesus severe (score of 5) disability. 


\section{Discussion}

The observation that GFAP levels were 3 -fold higher in the spinal cords of mice with chronic EAE compared to control animals is in keeping with the observation that extensive gliosis is a pathological hallmark of the late stages of the disease $[4,7]$. However gliosis is difficult to quantify by immuncytochemical techniques and usually done by counting cells, and the number and length of extending processes. The finding of grey matter astrogliosis and elevated GFAP levels is in line with previous results from human multiple sclerosis post-mortem tissue [6].

$\mathrm{NfH}^{\text {SMI35 }}$ levels were significantly lower in chronic EAE animals when compared to control animals. This biochemical result confirms the immunocytochemical observation of loss of axons in these animals $[7,1]$. In the light of recent data on axonal loss in MS [2,3] and severe axonal loss in the spinal cord of EAE [1], it is of particular interest that not only the overall staining intensity for $\mathrm{NfH}$ decreased, but also that axonal continuity almost completely disappeared. Counting axons might be particularly difficult in these situations and would only represent an estimate at the site of section. The measurement of the total $\mathrm{NfH}^{S M I 35}$ content is likely to be a more robust overall estimate of the bulk of remaining axons.

Ferritin and S100B are distinct from GFAP and $\mathrm{NfH}^{S M I 35}$ since they do not provide the scaffolding of the cytoskeleton, but are a product of the cellular metabolism for specific functional purposes. The decrease of ferritin suggests that the gliotic tissue transformation is paralleled by specific alteration of the glial metabolism. Whether or not this involves loss of neurotrophic support 
will need to be studied in experiments focusing on neurodegeneration.

In summary these findings demonstrate that axonal loss and gliosis can be quantified biochemically by measuring $\mathrm{NfH}^{S M I 35}$ and GFAP levels in the spinal cord tissue homogenate of animals with CREAE. These findings support the notion that brain-specific proteins emerge as surrogate markers and secondary outcome measures for neurodegenerative processes. The methods presented should be cross-validated with other markers and may provide time- and costeffective tools for experimental models investigating neurodegeneration.

\section{Acknowledgements}

The authors thank the Multiple Sclerosis Society of Great Britain and Northern Ireland for its support.

\section{References}

[1] J. Wujek, C. Bjartmar, E. Richer, et al., Axon loss in the spinal cord determines permanent neurological disability in an animal model of multiple sclerosis, J Neuropathol Exp Neurol 61 (2002) 23-32.

[2] C. Bjartmar, G. Kidd, S. Mork, R. Rudick, B. Trapp, Neurological disability correlates with spinal cord axonal loss and reduced $\mathrm{N}$-acetyl aspartate in chronic multiple sclerosis patients, Ann Neurol 48 (2000) 893-901.

[3] B. Trapp, J. Peterson, et al., Axonal transection in the lesions of multiple sclerosis, N Eng J Med 338 (1998) 278-285. 
[4] J. Newcombe, Distribution of glial fibrillary acidic protein in gliosed human white matter, J Neurochem 47 (1986) 1713-1719.

[5] R. Donato, S100: a multigenic family of calcium-modulated proteins of the EFhand type with intracellular and extracellular functional roles, Int J Biochem Cell Biol 33 (2001) 637-668.

[6] A. Petzold, M. Eikelenboom, D. Gveric, G. Keir, M. Chapman, R. Lazeron, et al., Markers for different glial cell responses in multiple sclerosis: Clinical and pathological correlations, Brain 125 (2002) 1462-1473.

[7] D. Baker, J. O’Neill, S. Gschmeissner, C. Wilcox, C. Butter, J. Turk, Induction of chronic relapsing experimental allergic encephalomyelitis in Biozzi mice, J Neuroimmunol 28 (1990) 261-270.

[8] D. Baker, G. Pryce, J. Croxford, et al., Cannabinoids control spasticity and tremor in a multiple sclerosis model, Nature 404 (2000) 84-87.

[9] A. Green, G. Keir, E. Thompson, A specific and sensitive ELISA for measuring S-100b in cerebrospinal fluid, J Immunol Meth 205 (1997) 35-41.

[10] G. Keir, N. Tasdemir, E. Thompson, Cerebrospinal-fluid ferritin in brain necrosis - evidence for local synthesis, Clin Chim Acta 216 (1993) 153-166. 
Table 1: Control (CTRL) and CREAE ABH mice spinal cord homogenate. Levels of brain-specific proteins are shown in $\mu \mathrm{g} / \mathrm{mg}$ protein. Median (range).

\begin{tabular}{llll} 
Protein ng/mg protein & CTRL mice & CREAE mice & $\mathrm{p}$-value \\
\hline GFAP & $4.5(1.4-5.2)$ & $13(5.0-26.4)$ & $\mathrm{p}<0.001$ \\
S100B & $2080(852-3107)$ & $786(219-1466)$ & N.S. \\
NfH & & & \\
Ferritin & $63(53-84)$ & $21(9-44)$ & $\mathrm{p}<0.001$ \\
& $858(794-1801)$ & $547(355-963)$ & $\mathrm{p}<0.001$ \\
Number & 7 & & \\
\hline
\end{tabular}


(A)

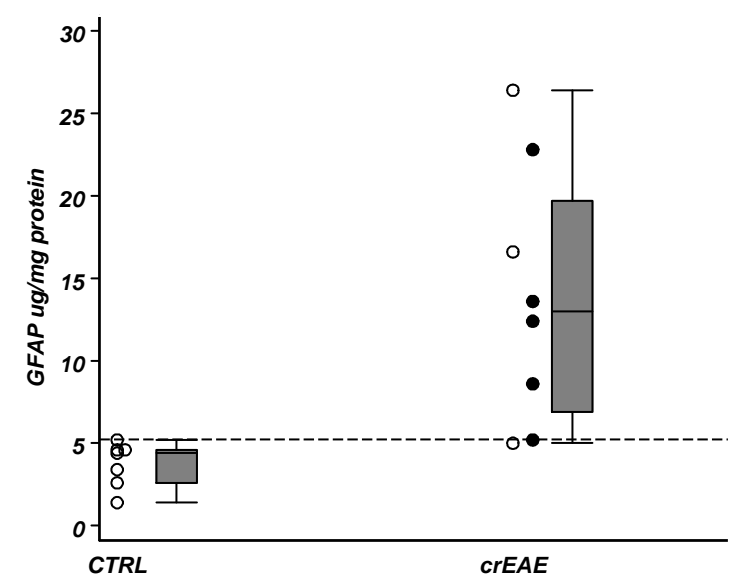

(C)

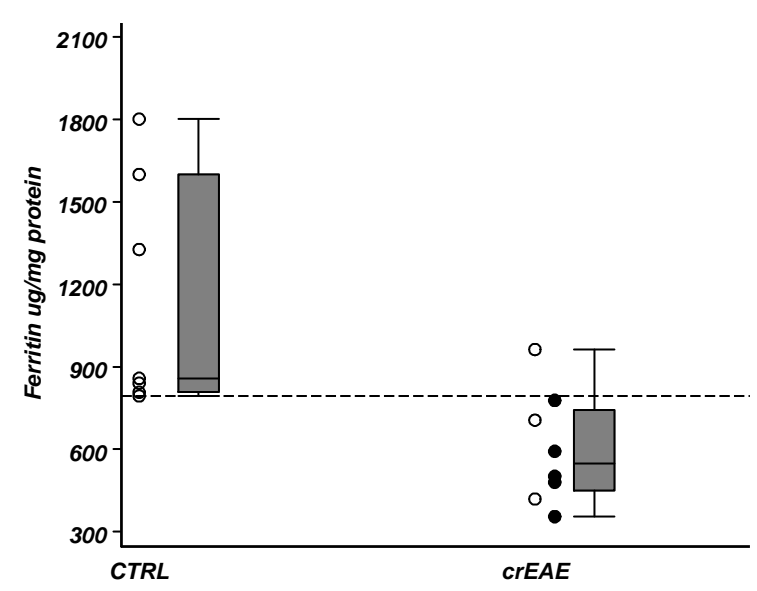

(B)

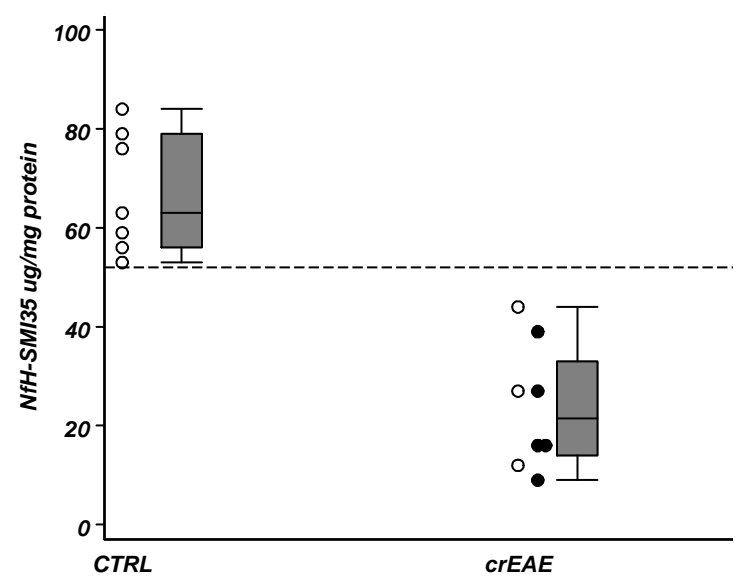

(D)

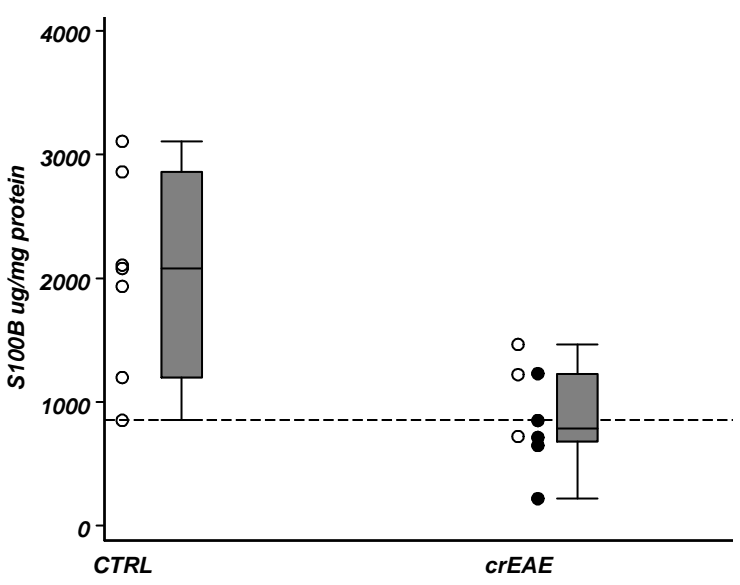

Fig. 1. Mice spinal cord tissue homogenates. Scatter and box-whisker plot for (A) GFAP (ng/mg protein), (B) NfH ${ }^{S M I 35}$ (ng/mg protein), (C) Ferritin (ng/mg protein) and (D) S100B (ng/mg protein) levels in control (CTRL) and chronic EAE 11 (CREAE) mice. Severely disabled animals are indicated by closed circles. 
control

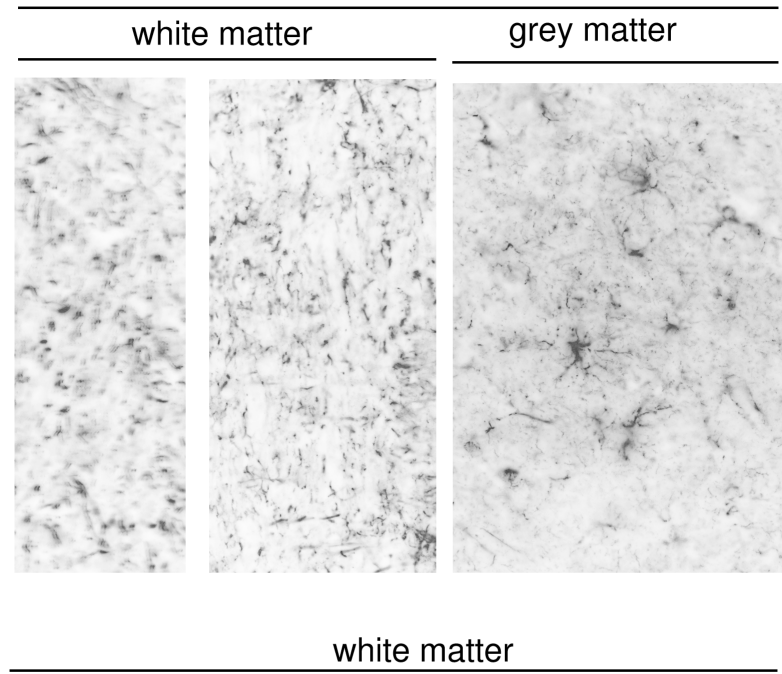

(B)

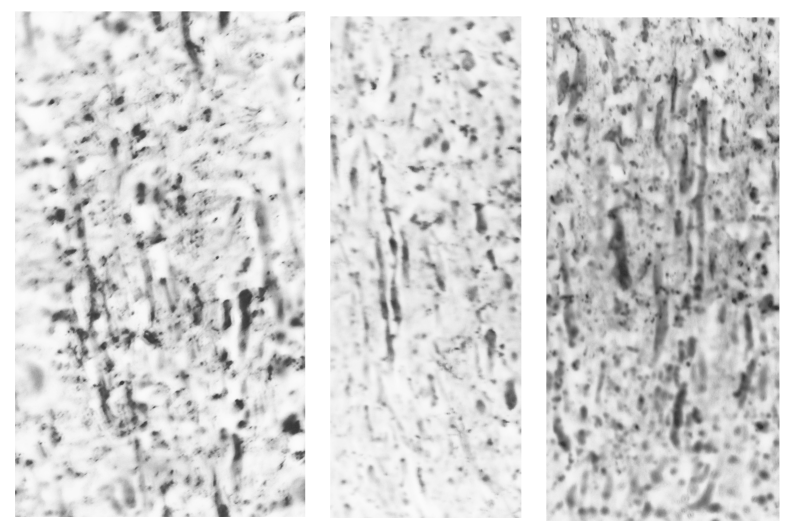

CREAE

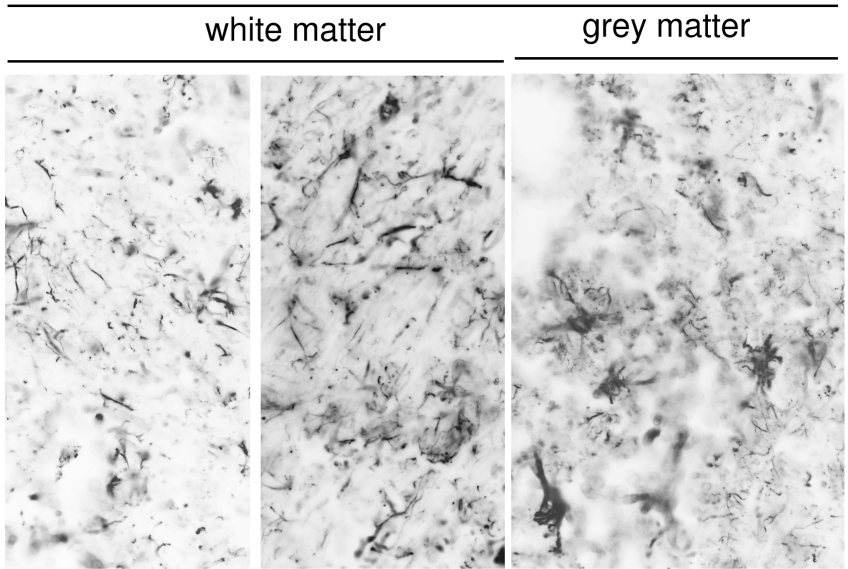

white matter

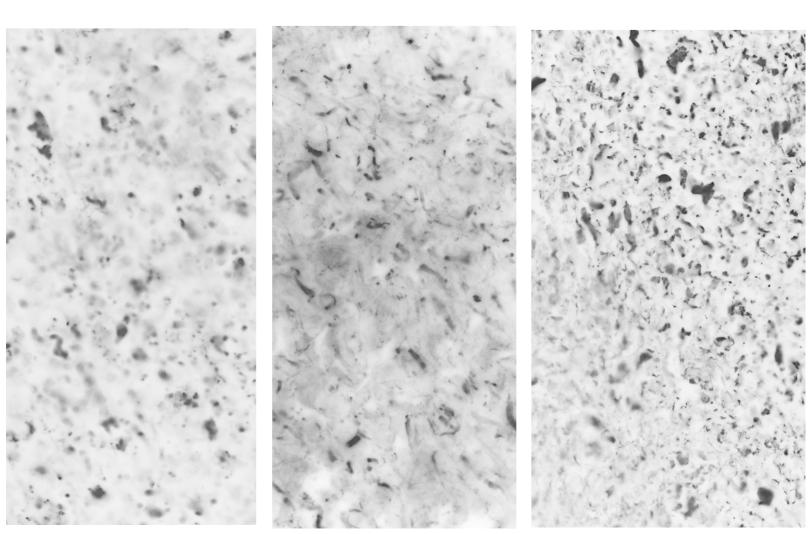

Fig. 2. Immunocytochemistry on longitudinal fresh frozen spinal cord sections of 3 control and 3 CREAE animals (x40). (A) GFAP staining for white and grey matter. More intense staining is observed in the CREAE spinal cord: in particular, the grey matter astrocytes are larger with more and longer processes. (B) NfH staining in white matter. Axonal tracts can be followed in control but not in CREAE animals. The staining in CREAE animals is less intense and many axonal end-bulbs are seen. 